\title{
Optimal time policy for deteriorating items of two-warehouse inventory system with time and stock dependent demand and partial backlogging
}

\author{
SHIV KUMAR* and ABHAY KUMAR SINGH \\ Department of Applied Mathematics, Indian School of Mines, Dhanbad 826004, India \\ e-mail: manshashiva@gmail.com
}

MS received 7 November 2015; revised 29 December 2015; accepted 4 January 2016

\begin{abstract}
We consider the problem of a two-warehouse inventory system under the effect of stock dependent demand. There are two warehouses to store the goods in which the first is rented warehouse and the second is own warehouse that deteriorates with two different rates. The aim of this study is to determine the optimal order quantity to maximize the profit of the projected model. Finally, some numerical examples and sensitivity analysis of parameters are made to validate the results of the proposed model.
\end{abstract}

Keywords. Deterioration; stock; profit; demand; warehouse; price.

\section{Introduction}

At the present time, various researchers have worked on single/two warehouse inventory system, which were calculated in a statics surroundings where the demand have been considered of various kinds such as constant demand, linear demand, time proportional, ramp type demand, time varying and time dependent. Many products of inventory like domestic goods, fashionable cloth, electronic product, tasty food products and domestic items are responsible for the increase in the sales after gaining costumer's acceptances. In this sense, many authors the over time have derived different strategies for single/two warehouses inventory system when shortage is allowed and partial backlogging depends on the waiting time [1-6]. Several authors have also studied inventory system without partial backlogging [7-15]. Goyal and Giri [16] developed the deteriorating inventory model without considering replacement policies for inventory which are subject to obsolescence. Jaggi and Tiwari [17] extended two-warehouse inventory model for non-instantaneous deteriorating items with price dependent demand and time-varying holding cost. Daultani et al [18] have done a supply chain network equilibrium model for operational and opportunism risk mitigation (table 1).

In this paper, the most important purpose of modeling the two-warehouse inventory is to determine the optimal order quantity in order to maximize the profit of the system. We have assumed that backlogging rate is exponentially decreasing with waiting time. It has been practically noticed in super market that the demand rate is regularly

*For correspondence

influenced by the current stock level. We have considered the item in the rented warehouse (RW) which has a lower deterioration rate while the item in own warehouse (OW) is decreasing with high deterioration rate. The necessary and sufficient condition for existence and uniqueness of the optimal solution are presented with some numerical example to demonstrate the developed model.

The variation of inventory level per cycle is expressed as depicted in figure 1.

Considering the two-warehouse inventory system such that the capacity of OW inventory system is $Q$ and the capacity of RW is unlimited. Initial demand is satisfied from an RW after that items are consumed from OW. Initially during the period $\left[0, t_{0}\right]$, RW inventory level depletes due to deterioration as well as demand at the same period whereas OW depletes due to deterioration only. During the period $\left[t_{0}, t_{1}\right]$ inventory level of $\mathrm{OW}$ decreases due to demand as well as deterioration.

The following fundamental notations and assumptions are used to derive the solution of the model.

\section{Notations}

A

a

$b$

$h_{r}$

$h_{o}$

$c_{d}$

$c_{S}$

$c_{l}$

$c$ ordering cost per period initial demand of items parameter of demand governing increasing $(b>0)$ or decreasing $(b<0)$ trend, $b<a$ the holding cost per unit item of RW the holding cost per unit item of OW cost of deteriorated unit shortage cost per unit per unit time lost sale cost per unit purchase cost per unit item 


$\begin{array}{ll}t_{0} & \begin{array}{l}\text { the time when inventory of RW becomes } \\ \text { empty } \\ t_{1}\end{array} \\ T & \begin{array}{l}\text { time when inventory level reaches to zero } \\ \text { the replenishment cycle }\end{array} \\ T P F\left(t_{0}, t_{1}, T\right) & \begin{array}{l}\text { average profit of the system } \\ \text { inventory level at of RW at any time } t, \\ I_{r}(t)\end{array} \\ & \begin{array}{l}0<t<t_{0} \\ I_{01}(t)\end{array} \\ I_{02}(t) & \text { inventory level OW at any time } t, 0 \leq t \leq t_{0} \\ I_{03}(t) & \begin{array}{l}t_{0} \leq t \leq t_{1} \\ \text { inventory level OW at any time } t, \\ t_{1} \leq t \leq T\end{array} \\ O Q^{*} & \text { shortage level } \\ \alpha & \text { optimal Ordering quantity } \\ \beta & \text { deterioration rate of RW } \\ \text { deterioration rate of OW }\end{array}$

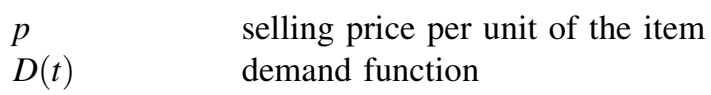

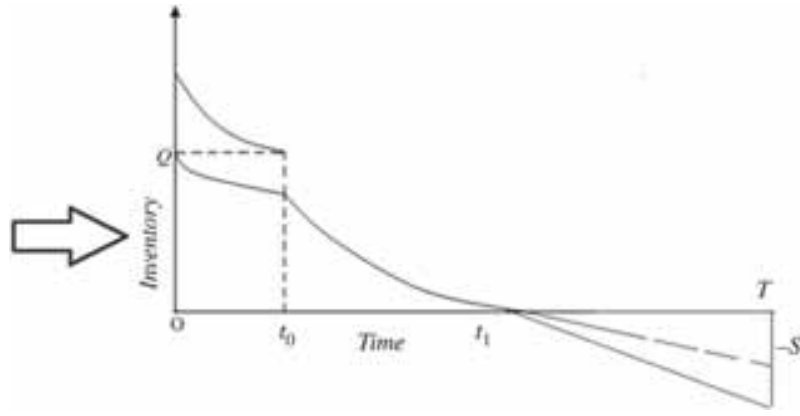

Figure 1. Geometry of the problem.

Table 1. Summary of related literature for inventory models with partial backlogging and without partial backlogging.

\begin{tabular}{|c|c|c|c|c|c|c|}
\hline References & Demand rate & Deterioration rate & $\begin{array}{l}\text { Single/two } \\
\text { warehouse }\end{array}$ & $\begin{array}{l}\text { Under } \\
\text { inflation }\end{array}$ & $\begin{array}{l}\text { With partial } \\
\text { backlogging }\end{array}$ & $\begin{array}{l}\text { Allow for } \\
\text { shortage }\end{array}$ \\
\hline $\begin{array}{l}\text { Chakrabarty et al } \\
\text { [7] }\end{array}$ & Linear demand & $\begin{array}{c}\text { Three-parameter Weibull } \\
\text { distribution }\end{array}$ & $\begin{array}{l}\text { Single } \\
\text { warehouse }\end{array}$ & No & No & Yes \\
\hline $\begin{array}{l}\text { Covert and Philip } \\
\text { [15] }\end{array}$ & Constant & $\begin{array}{c}\text { Two-parameter Weibull } \\
\text { distribution }\end{array}$ & $\begin{array}{l}\text { Single } \\
\text { warehouse }\end{array}$ & No & No & No \\
\hline Dave and Patel [8] & Time proportional & Constant & $\begin{array}{l}\text { Single } \\
\text { warehouse }\end{array}$ & No & No & No \\
\hline $\begin{array}{l}\text { Ghare and Shrader } \\
\text { [9] }\end{array}$ & Constant & Constant & $\begin{array}{l}\text { Single } \\
\text { warehouse }\end{array}$ & No & No & No \\
\hline Giri et al [10] & $\begin{array}{r}\text { Ramp-type } \\
\text { demand }\end{array}$ & $\begin{array}{c}\text { Three-Parameter Weibull } \\
\text { distribution }\end{array}$ & $\begin{array}{l}\text { Single } \\
\text { warehouse }\end{array}$ & No & No & Yes \\
\hline Hariga [11] & $\begin{array}{c}\text { Time varying }(\log \\
\text { concave) }\end{array}$ & Constant & $\begin{array}{l}\text { Single } \\
\text { warehouse }\end{array}$ & No & No & Yes \\
\hline Lo et al [4] & Constant & $\begin{array}{c}\text { Two-parameter Weibull } \\
\text { distribution }\end{array}$ & $\begin{array}{l}\text { Single } \\
\text { warehouse }\end{array}$ & Yes & Yes & Yes \\
\hline Misra [12] & Constant & $\begin{array}{c}\text { Two-parameter Weibull } \\
\text { distribution }\end{array}$ & $\begin{array}{l}\text { Single } \\
\text { warehouse }\end{array}$ & No & No & No \\
\hline Philip [13] & Constant & $\begin{array}{c}\text { Three-parameter Weibull } \\
\text { distribution }\end{array}$ & $\begin{array}{l}\text { Single } \\
\text { warehouse }\end{array}$ & No & No & No \\
\hline $\begin{array}{l}\text { Skouri and } \\
\text { Konstantaras [5] }\end{array}$ & Time dependent & $\begin{array}{c}\text { Two-parameter Weibull } \\
\text { distribution }\end{array}$ & $\begin{array}{l}\text { Single } \\
\text { warehouse }\end{array}$ & No & Yes & Yes \\
\hline Skouri et al [1] & Ramp-type & $\begin{array}{c}\text { Two-parameter Weibull } \\
\text { distribution }\end{array}$ & $\begin{array}{l}\text { Single } \\
\text { warehouse }\end{array}$ & No & Yes & Yes \\
\hline Teng et al [14] & Time varying & Constant & $\begin{array}{l}\text { Single } \\
\text { warehouse }\end{array}$ & No & No & Yes \\
\hline Wee et al [2] & Constant & $\begin{array}{c}\text { Two-parameter Weibull } \\
\text { distribution }\end{array}$ & $\begin{array}{l}\text { Two } \\
\text { warehouse }\end{array}$ & Yes & Yes & Yes \\
\hline Yang [3] & Constant & Constant & $\begin{array}{l}\text { Two } \\
\text { warehouse }\end{array}$ & Yes & Yes & Yes \\
\hline Yang [6] & Constant & $\begin{array}{c}\text { Three-parameter Weibull } \\
\text { distribution }\end{array}$ & $\begin{array}{c}\text { Two } \\
\text { warehouse }\end{array}$ & Yes & Yes & Yes \\
\hline $\begin{array}{l}\text { Jaggi and Tiwari } \\
\text { [17] }\end{array}$ & $\begin{array}{r}\text { Selling price } \\
\text { dependent }\end{array}$ & Constant & $\begin{array}{c}\text { Two } \\
\text { warehouse }\end{array}$ & No & No & Yes \\
\hline $\begin{array}{l}\text { Present paper } \\
\quad(2015)\end{array}$ & Stock dependent & Constant & $\begin{array}{l}\text { Two } \\
\text { warehouse }\end{array}$ & No & Yes & Yes \\
\hline
\end{tabular}




\section{Assumptions}

1. Deterioration rates of items in OW and RW are $\alpha$ and $\beta$ respectively such that $\alpha>\beta$.

2. The holding cost per unit item of OW $h_{o}$ and RW $h_{r}$ respectively are chosen such that $h_{o}<h_{r}$.

3. The demand function $D(p)$, which is assumed as stock dependent with time is expressed as $D(p)=$ $\left\{\begin{array}{ll}a+b I(t), & I(t) \geq 0 \\ a, & I(t) \leq 0\end{array}\right.$ where $a, \mathrm{~b}$ are positive constant and $I(t)$ is inventory level at any time $t$.

4. The OW has limited capacity of units while the RW has unlimited capacity. Initially demands are satisfied from RW and then from OW.

5. Lead time is zero and replenishment is instantaneous.

6. Shortages are allowed and partial backlogging rate is exponentially decreasing with waiting time and it is defined as $B(T-t)=e^{-\delta(T-t)}$ where $\delta$ is positive constant and $(T-t)$ is waiting time up to next replenishment.

Mathematical model and its solution

The inventory levels in RW are given by the following differential equation

$$
\frac{\mathrm{d} I_{r}(t)}{\mathrm{d} t}+\beta I_{r}(t)=-\left(a+b I_{r}(t)\right), \quad 0 \leq t \leq t_{0}
$$

with initial conditions $I_{r}(t)=0$ at $t=t_{0}$.

The inventory levels in OW are given by the following differential equation

$$
\frac{\mathrm{d} I_{o 1}(t)}{\mathrm{d} t}+\alpha I_{o 1}(t)=0, \quad 0 \leq t \leq t_{0}
$$

With boundary conditions $I_{o 1}(t)=Q$ at $t=0$,

The solution of Eqs. (1) and (2) using above boundary condition is respectively given as follows:

$$
\begin{gathered}
I_{r}(t)=\frac{a}{(\beta+b)}\left[e^{(\beta+b)\left(t_{0}-t\right)}-1\right], \quad 0 \leq t \leq t_{0} \\
I_{o 1}(t)=Q e^{-\alpha t}, \quad 0 \leq t \leq t_{0}
\end{gathered}
$$

Again, in the interval $\left[t_{0}, t_{1}\right]$, the inventory depleted due to the joint effect of the demand and deterioration. The inventory level in OW is given by the following differential equation

$$
\frac{\mathrm{d} I_{o 2}(t)}{\mathrm{d} t}+\alpha I_{o 2}(t)=-\left(a+b I_{o 2}(t)\right), \quad t_{0} \leq t \leq t_{1} .
$$

With boundary conditions $I_{o 2}(t)=0$, when at $\mathrm{t}=t_{1}$ The solution of Eq. (5) given by

$$
I_{o 2}(t)=\left(\frac{a}{\alpha+b}\right)\left[e^{(\alpha+b)\left(t_{1}-t\right)}-1\right], \quad t_{0} \leq t \leq t_{1}
$$

From Eqs. (4) and (6), due to continuity at $t=t_{0}$ we get

$$
\begin{aligned}
& I_{o 1}(t)=I_{o 2}(t) \\
& \Rightarrow Q e^{-\alpha t_{0}}=\left(\frac{a}{\alpha+b}\right)\left(-1+e^{(\alpha+b)\left(t_{1}-t_{0}\right)}\right) \\
& \Rightarrow Q=\left(\frac{a e^{-\alpha t_{0}}}{\alpha+b}\right)\left(-1+e^{(\alpha+b)\left(t_{1}-t_{0}\right)}\right) \\
& \Rightarrow t_{1}=t_{0}+\left(\frac{1}{\alpha+b}\right) \ln \left(\frac{a+Q(\alpha+b) e^{-\alpha t_{0}}}{a}\right)
\end{aligned}
$$

Equation (7) shows that $t_{1}$ is a function of $t_{0}$. Now taking the first order derivative of $t_{1}$ with respect to $t_{0}$ we get

$$
\frac{\mathrm{d} t_{1}}{\mathrm{~d} t_{0}}=\left[1-\left\{\frac{Q \alpha}{a e^{\alpha t_{o}}+Q(\alpha+b)}\right\}\right]
$$

$\frac{\mathrm{d} t_{1}}{\mathrm{~d} t_{0}}-1<0$ holds. Furthermore, at time $t_{1}$ the inventory level becomes zero in OW and shortage occurs.

The variation of shortage level $I(t)$ during the inventory level $\left[t_{1}, \mathrm{~T}\right]$ is described by the differential equation

$$
\frac{\mathrm{d} I_{03}(t)}{\mathrm{d} t}=-a e^{-\delta(T-t)}, \quad t_{1} \leq t \leq T
$$

With boundary condition $I_{03}(t)=0$ when at $t=t_{1}$ then the solution of Eq. (8) is represented by

$$
I_{03}(t)=\frac{a}{\delta}\left[e^{-\delta\left(T-t_{1}\right)}-e^{\delta(T-t)}\right]
$$

Now at time $t=T, I_{03}(t) \equiv-S$ Eq. (9)

$$
S \equiv-I_{03}(T)=-\frac{a}{\delta}\left[e^{-\delta\left(T-t_{1}\right)}-1\right]
$$

Required amount of order quantity are

$$
\begin{aligned}
O Q & =\left[\left\{Q+I_{r}(0)\right\}+S\right] \text { Or } \\
& \Rightarrow O Q=\left[\left\{Q+\frac{a}{(\beta+b)}\left[e^{(\beta+b) t_{0}}-1\right]\right\}+S\right],
\end{aligned}
$$

The various cost and sales revenue for proposed model per cycle is as follows:

(i) Ordering cost per cycle is A.

(ii) Inventory holding/storage cost of the system consists of holding cost $H C_{r}$ in RW and holding cost $H C_{o}$ in $\mathrm{OW}$ respectively is

$$
\begin{aligned}
H C_{r} & =h_{r} \int_{0}^{t_{0}} I_{r}(t) \mathrm{d} t \Rightarrow H C_{r} \\
& =h_{r}\left[-\frac{a}{(\beta+b)}\left\{t_{0}+\frac{1}{(\beta+b)}\left(1-e^{(\beta+b) t_{0}}\right)\right\}\right]
\end{aligned}
$$

and 


$$
\begin{aligned}
H C_{o}= & h_{0}\left[\int_{0}^{t_{0}} I_{01}(t) \mathrm{d} t+\int_{t_{0}}^{t_{1}} I_{02}(t) \mathrm{d} t\right] \\
\Rightarrow & H C_{0}=h_{o}\left[\frac{Q}{\alpha}\left(1-e^{-\alpha t_{0}}\right)+\frac{a}{(\alpha+b)}\right. \\
& \left.\times\left(t_{0}-t_{1}+\frac{1}{(\alpha+b)}\left(e^{(\alpha+b)\left(t_{1}-t_{0}\right)}-1\right)\right)\right] .
\end{aligned}
$$

(iii) The deterioration cost per cycle is represented by

$$
\begin{aligned}
D C= & c_{d}\left[\beta \int_{0}^{t_{0}} I_{r}(t) \mathrm{d} t+\alpha \int_{0}^{t_{0}} I_{01}(t) \mathrm{d} t+\alpha \int_{0}^{t_{0}} I_{02}(t) \mathrm{d} t\right] \\
\Rightarrow & D C=c_{d}\left[-\frac{(\beta a)}{(\beta+b)}\left\{t_{0}+\frac{1}{(\beta+b)}\left(1-e^{(\beta+b) t_{0}}\right)\right\}\right. \\
& +Q\left(1-e^{-\alpha t_{0}}\right)+\frac{\alpha a}{(\alpha+b)}\left\{t_{0}-t_{1}\right. \\
& \left.\left.+\frac{1}{(\alpha+b)}\left(e^{(\alpha+b)\left(T-t_{0}\right)}-1\right)\right\}\right] .
\end{aligned}
$$

(iv) Purchase cost $P C$ for the order quantity is expressed as

$$
\begin{aligned}
& P C=c(O Q) \\
& \Rightarrow P C=c\left[\left\{Q+\frac{a}{(\beta+b)}\left[e^{(\beta+b) t_{0}}-1\right]\right\}+S\right],
\end{aligned}
$$

(v) The cost due to lost sales is given by

$$
\begin{aligned}
& L C=c_{l} \int_{t_{1}}^{T} D(p)\left(1-e^{-\delta(T-t)}\right) \mathrm{d} t \\
& \Rightarrow L C=a c_{l}\left[\left(T-t_{1}\right)+\frac{1}{\delta}\left(e^{-\delta\left(T-t_{1}\right.}\right)\right]
\end{aligned}
$$

(vi) The shortage cost in the entire cycle is described by

$$
\begin{aligned}
& S C=-c_{s} \int_{t_{1}}^{T} I_{03}(t) \mathrm{d} t \\
& =-\frac{a c_{s}}{\delta} \int_{t_{1}}^{T}\left[e^{-\delta\left(T-t_{1}\right)}-e^{\delta(T-t)}\right] \mathrm{d} t \\
& \Rightarrow S C=-\frac{a c_{s}}{\delta}\left[\frac{1}{\delta}\left(1-e^{\delta\left(T-t_{1}\right)}\right)\right. \\
& \left.+T e^{-\delta\left(T-t_{1}\right)}-t_{1} e^{-\delta\left(T-t_{1}\right)}\right]
\end{aligned}
$$

(vii) Total sales revenue $S R$ is represented by

$$
\begin{aligned}
S R & =p\left[\int_{0}^{t_{1}} D(t) \mathrm{d} t-I_{03}(T)\right] \\
\Rightarrow & S R=p\left[-\frac{a b}{(\beta+b)}\left\{t_{0}+\frac{1}{(\beta+b)}\left(1-e^{(\beta+b) t_{0}}\right)\right\}\right. \\
& +a t_{1}+b\left\{t_{0}-t_{1}-\frac{1}{(\alpha+b)}\left(1-e^{(\alpha+b)\left(T-t_{0}\right)}\right)\right\} \\
& \left.-\frac{a}{\delta}\left\{e^{-\delta\left(T-t_{1}\right)}-1\right\}\right]
\end{aligned}
$$

Total profit of the system per unit time $\operatorname{TPF}\left(t_{0}^{*}, t_{1}^{*}, T^{*}\right)$ is given by

$$
\begin{aligned}
T P F\left(t_{0}, t_{1}, T\right)= & \frac{1}{T}\left[S R-\left(A+H C_{r}+H C_{O}+D C+P C\right.\right. \\
& +S C+L C)]
\end{aligned}
$$

Case 1: The profit of the system per unit time per cycle $\operatorname{TPF}\left(t_{0}, t_{1}, T\right)$ becomes a function of only $t_{0}$.

Now in this case the profit of the system per unit time per cycle is expressed as

$T P F\left(t_{0}\right)=\frac{1}{T}\left[S R-\left(A+H C_{r}+H C_{O}+D C+P C+S C+L C\right)\right]$

The optimal value of $t_{0}$ that is $t_{0}^{*}$ obtained by satisfying the following necessary condition $\frac{\partial T P F\left(t_{0}\right)}{\partial t_{0}}=0$, along with the following sufficient condition $\left[\frac{\partial^{2} T P F\left(t_{0}\right)}{\partial t_{0}^{2}}\right]_{a t\left(t=t_{0}^{*}\right)}<0$

Case 2: The profit of the system per unit time per cycle $\operatorname{TPF}\left(t_{0}, t_{1}, T\right)$ is a function of only $t_{1}$.

Now in this case the profit of the system per unit time per cycle is expressed as

$T P F\left(t_{1}\right)=\frac{1}{T}\left[S R-\left(A+H C_{r}+H C_{O}+D C+P C+S C+L C\right)\right]$

The optimal value of $t_{1}$ that is $t_{1}^{*}$ obtained by satisfying the following necessary condition $\frac{\partial T P F\left(t_{1}\right)}{\partial t_{1}}=0$, along with the following sufficient condition $\left[\frac{\partial^{2} T P F\left(t_{1}\right)}{\partial t_{1}^{2}}\right]_{a t\left(t=t_{1}^{*}\right)}<0$

Case 3: The profit of the system per unit time per cycle $\operatorname{TPF}\left(t_{0}, t_{1}, T\right)$ is a function of only $T$.

Now in this case the profit of the system per unit time per cycle is expressed as 
$T P F(T)=\frac{1}{T}\left[S R-\left(A+H C_{r}+H C_{O}+D C+P C+S C+L C\right)\right]$

The optimal value of $T$ that is $T^{*}$ obtained by satisfying the following necessary condition $\frac{\partial T P F(T)}{\partial T}=0$, along with the following sufficient condition $\left[\frac{\partial^{2} T P F(T)}{\partial T^{2}}\right]_{a t\left(t=T^{*}\right)}<0$

\section{Numerical result, graphical representation and sensitivity analysis}

The required optimal values for a two-warehouse deteriorating inventory system with the parameter $a, b, \delta, \alpha$, and $\beta$, are calculated using the Newton Rapshon method. We have computed numerical values in example 2.1, 2.2, and 2.3 as well as their graphical represent which are shown in figure 2, figure 3, and figure 4 using Mathematica software to study the effects of various parameters on profit used in the model that can be seen from table 2, table 3, and table 4 given below. Table 2, table 3 , and table 4 show the sensitivity of the various parameters on optimal average profit $T P F_{\text {, }}^{*}$ optimal ordering quantity $O Q^{*}$ and optimal time of on hand inventory.

\subsection{Example}

$c_{d}=\$ 1 /$ unit, $c=\$ 1 /$ per unit, $\mathrm{c}_{1}=\$ 1 /$ per unit,$h_{r}=1$,

$h_{0}=\$ 0.25 /$ per unit/per unit time,

$\mathrm{c}_{\mathrm{s}}=\$ 1 /$ per unit/per unit time, $p=\$ 10 /$ unit ,

$\mathrm{a}=100$ unit $/$ month $, \mathrm{b}=0.30, \delta=0.05, \alpha=0.40$,

$\beta=0.2, A=\$ 2 /$ per order, $Q=100$,

$\mathrm{t}_{1}=2$ month, $\mathrm{T}=6$ month,

Optimal time of on hand inventory in RW $t_{0}^{*}=3.27034$ month

Optimal average profit of the system $T P F^{*}=\$ 228.0013$

Optimal order quantity $O Q^{*}=1288.60$

\section{Graphical representation}

Graphical representation of the effect of time $t_{0}$ on profit is done in figure 2 as follows:

\section{Sensitivity analysis}

Sensitivity analysis is carried out by changing the specified parameter $a, b, \delta, \alpha$ and $\beta$ by $-50 \%,-25 \%,+25 \%$, and $+50 \%$ keeping the remaining parameter at their standard value.

The study manifested table 2 following facts.

1. When the change in the value of its parameters $a, b$ and the backlogging parameter $\delta$ then optimal average profit $T P F^{*}$ is highly sensitive to demand. It is slightly

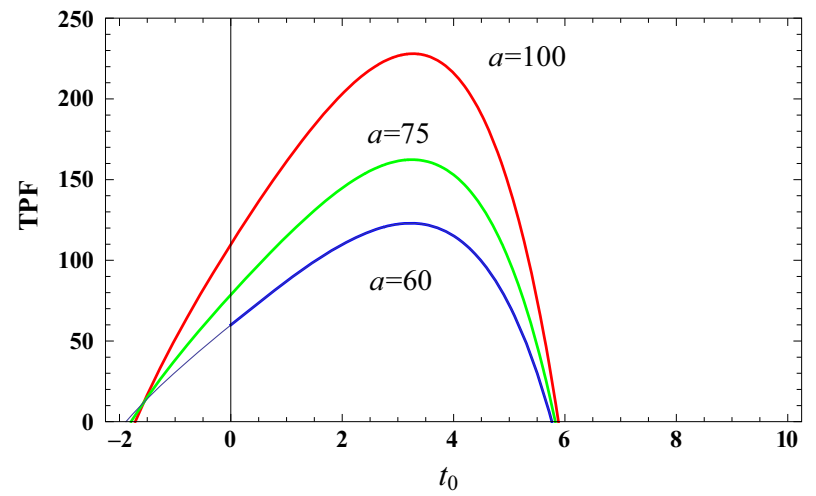

Figure 2. Variation of profit with respect to time $t_{0}$.

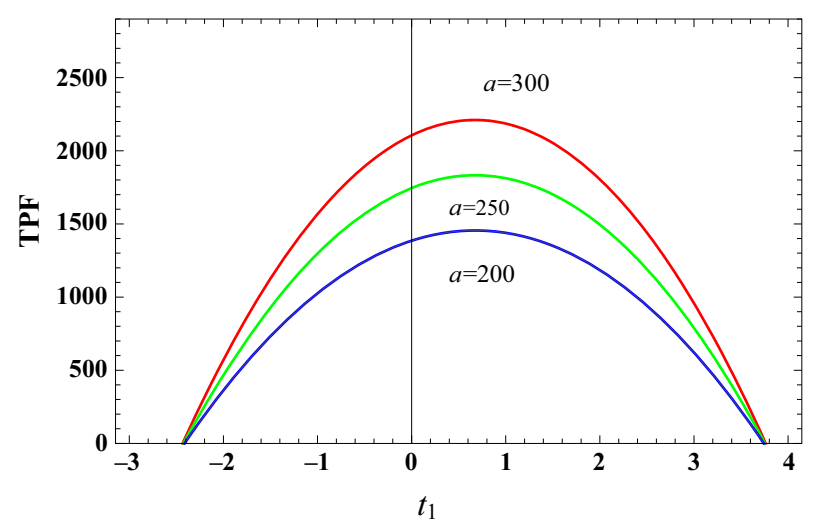

Figure 3. Variation of profit with respect to time $t_{1}$.

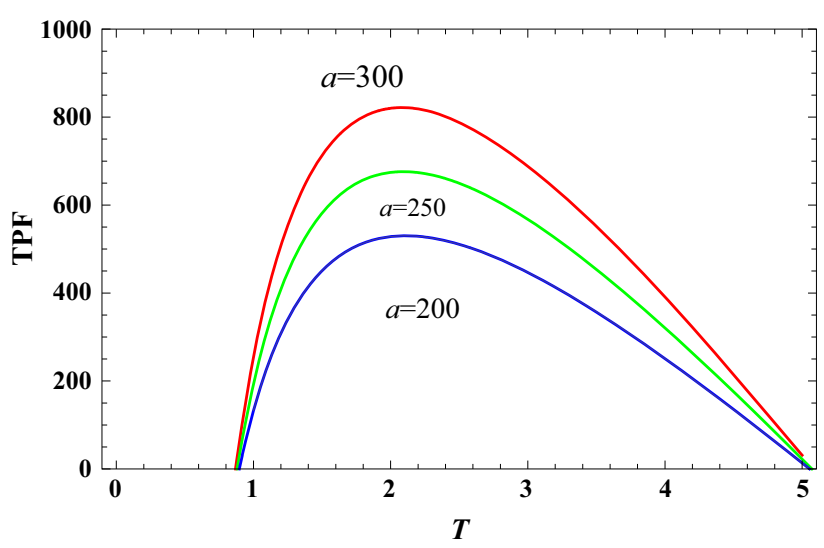

Figure 4. Variation of profit with respect to time $T$.

sensitive to the change in $\beta$ and moderately sensitive to changes in $\alpha$.

2. The study reflects that optimal order quantities $O Q^{*}$ is highly sensitive to the change in demand parameter $a$ and $b$ whereas moderately sensitive of $O Q^{*}$ is observed 
Table 2. Sensitivity analysis by changing the specified parameter $a, b, \delta, \alpha$ and $\beta$ in percentages.

\begin{tabular}{lrrrr}
\hline Parameter & Change $\%$ & \multicolumn{1}{c}{$t_{0}^{*}$} & \multicolumn{1}{c}{$O Q^{*}$} & \multicolumn{1}{c}{$P F^{*}$} \\
\hline$a$ & -50 & -2.02 & -47.41 & -57.57 \\
& -25 & -0.64 & -23.69 & -28.57 \\
& +25 & +0.37 & +23.68 & +28.80 \\
& +50 & +0.62 & +47.35 & +57.60 \\
$b$ & -50 & +83.69 & +95.226 & +169.84 \\
& -25 & +33.98 & +35.18 & +56.02 \\
& +25 & -25.35 & -22.67 & -29.41 \\
& +50 & -46.44 & -38.77 & -45.24 \\
$\delta$ & -50 & 0.00 & +1.40 & +10.04 \\
& -25 & 0.00 & +0.69 & +4.97 \\
& +25 & 0.00 & -0.66 & -4.87 \\
$\alpha$ & +50 & 0.00 & -1.31 & -9.65 \\
& -50 & +1.61 & +2.13 & +1.74 \\
& -25 & +0.72 & +0.95 & +0.75 \\
& +25 & -0.62 & -0.80 & -0.59 \\
& +50 & -1.17 & -1.51 & -1.06 \\
& -50 & -9.24 & -19.90 & -37.07 \\
& -25 & +0.37 & -50.80 & -15.43 \\
& +25 & -3.17 & +2.29 & +10.58 \\
& +50 & -7.22 & +2.81 & +17.69 \\
\hline
\end{tabular}

Table 3. Sensitivity analysis by changing the specified parameter $a, b, \delta, \alpha$ and $\beta$ in percentages.

\begin{tabular}{lcccr}
\hline Parameter & Change $\%$ & $t_{1}^{*}$ & $O Q^{*}$ & \multicolumn{1}{c}{$P F^{*}$} \\
\hline$a$ & -50 & 0.00 & -41.89 & -51.51 \\
& -25 & 0.00 & -20.94 & -25.62 \\
& +25 & 0.00 & +20.94 & +25.62 \\
& +50 & 0.00 & +41.89 & +51.24 \\
$b$ & -50 & 0.00 & -0.07 & +50.61 \\
& -25 & 0.00 & -0.07 & +20.24 \\
& +25 & 0.00 & +0.03 & -14.45 \\
$\delta$ & +50 & 0.00 & +0.7 & -25.28 \\
& -50 & -0.93 & +0.47 & +0.09 \\
& -25 & -0.49 & +0.23 & +0.04 \\
& +25 & +0.45 & -0.23 & -0.04 \\
$\alpha$ & +50 & +0.93 & -0.47 & -0.09 \\
& -50 & +0.34 & -0.11 & +0.04 \\
& -25 & +0.17 & -0.05 & +0.01 \\
& +25 & -0.16 & +0.05 & -0.01 \\
& +50 & -0.32 & +0.13 & -0.03 \\
& -50 & 0.00 & -0.03 & +13.76 \\
& -25 & 0.00 & -0.01 & 6.25 \\
& +25 & 0.00 & +0.01 & -5.38 \\
& +50 & 0.00 & +0.03 & -9.83 \\
\hline & & & &
\end{tabular}

to the $\beta$ while it is slightly sensitive to change in $\alpha$ and backlogging parameter $\delta$.

3. $t_{0}^{*}$ is slightly sensitive to the change in the parameter $\beta$ also it is observed that it is highly sensitive to the change in the parameter $a$ and $b$ whereas it is moderately sensitive to $\delta$ and $\alpha$.
Table 4. Sensitivity analysis by changing the specified parameter $a, b, \delta, \alpha$ and $\beta$ in percentages.

\begin{tabular}{lcccc}
\hline Parameter & Change $\%$ & $T^{*}$ & $O Q^{*}$ & $P F^{*}$ \\
\hline$a$ & -50 & 0.00 & -40.03 & -52.67 \\
& -25 & 0.00 & -20.01 & -26.33 \\
& +25 & 0.00 & +20.01 & +26.33 \\
& +50 & 0.00 & +40.03 & +52.67 \\
$b$ & -50 & 0.00 & -0.24 & +113.11 \\
& -25 & 0.00 & -0.12 & +37.92 \\
& +25 & 0.00 & +0.37 & -49.00 \\
$\delta$ & +50 & 0.00 & +0.24 & -38.06 \\
& -50 & +1.81 & +2.01 & -0.22 \\
& -25 & +1.60 & +0.97 & -0.11 \\
& +25 & +0.64 & -0.95 & +0.11 \\
$\alpha$ & +50 & +0.27 & -1.87 & +0.22 \\
& -50 & 0.00 & 0.00 & +0.56 \\
& -25 & 0.00 & 0.00 & +0.28 \\
& +25 & 0.00 & 0.00 & -0.28 \\
& +50 & 0.00 & 0.00 & -0.56 \\
& -50 & 0.00 & -0.002 & +0.28 \\
& -25 & 0.00 & -0.001 & +0.14 \\
& +25 & 0.00 & +0.001 & -0.14 \\
& +50 & 0.00 & +0.002 & -0.28 \\
\hline & & & &
\end{tabular}

\subsection{Example}

$c_{d}=\$ 1 /$ unit,$c=\$ 1 /$ per unit,$c_{1}=\$ 1 /$ per unit,

$h_{r}=\$ 1 /$ per unit $/$ per unit time,

$h_{o}=\$ 0.25 /$ per unit $/$ per unit time,

$\mathrm{c}_{\mathrm{s}}=\$ 1 /$ per unit $/$ per unit time,$p=\$ 5 /$ unit,

$\mathrm{a}=300$ unit $/$ month $, \mathrm{b}=0.04, \delta=0.008, \alpha=0.04$,

$\beta=0.02, A=\$ 1 /$ per order, $Q=100$,

$\mathrm{t}_{0}=0.40$ month, $\mathrm{T}=2$ month,

Optimal time of on hand inventory $t_{1}^{*}=0.6749$ month

Optimal average profit of the system $T P F^{*}=\$ 2209.92$

Optimal order quantity $O Q^{*}=616$.

\section{Graphical representation}

Graphical representation of the effect of time $t_{1}^{*}$ on profit is done in figure 3 as follows:

Sensitivity analysis

Sensitivity analysis is carried out by changing the specified parameter $a, b, \delta, \alpha$ and $\beta$ by $-50 \%,-25 \%,+25 \%$, and $+50 \%$ keeping the remaining parameter at their standard value.

The study manifested table 3 following facts.

1. $t_{1}^{*}$ is no sensitive to the change in the parameter $a, b$, and $\beta$ but it is also obtained that it is moderately sensitive to the vary in the parameter $\alpha$ and slightly sensitive in $\delta$.

2. The study of observation that optimal order quantity $O Q^{*}$ is highly sensitive to the change in demand 
parameter $a$ whereas moderately sensitive of $O Q^{*}$ is observed to the $b, \alpha, \beta$ while it is slightly sensitive to change in backlogging parameter $\delta$.

3. Optimal average profit $T P F^{*}$ is highly sensitive due to the change in the value of its parameters $a, b$ and it is slightly sensitive to the change in $\beta$ and there is moderately sensitive to changes in $\alpha$ and the backlogging parameter $\delta$.

\subsection{Example}

$$
\begin{aligned}
& c_{d}=\$ 1 / \text { unit }, c=\$ 1 / \text { per unit }, \mathrm{c}_{1}=\$ 1 / \text { per unit }, \\
& h_{r}=\$ 1 / \text { per unit } / \text { per unit time, } \\
& h_{o}=\$ 0.25 / \text { per unit } / \text { per unit time, } \\
& \mathrm{c}_{\mathrm{s}}=\$ 1 / \text { per unit } / \text { per unit time }, p=\$ 4 \text { per unit, } \\
& \mathrm{a}=300 \text { units } / \text { month }, \mathrm{b}=0.10, \delta=0.05, \alpha=0.04, \\
& \beta=0.001, A=\$ 2 / \text { per order }, Q=100, \\
& \mathrm{t}_{0}=0.40 \text { month }, \mathrm{t}_{1}=2 \text { month },
\end{aligned}
$$

Optimal time of on hand inventory $T^{*}=2.9525$ month Optimal average profit of the system $T P F^{*}=\$ 699.942$ Optimal order quantity $O Q^{*}=501.513$.

\section{Graphical representation}

Graphical representation of the effect of time Ton profit is done in figure 4 as follows:

\section{Sensitivity analysis}

Sensitivity analysis is carried out by changing the specified parameter $a, b, \delta, \alpha$ and $\beta$ by $-50 \%,-25 \%,+25 \%$, and $+50 \%$ keeping the remaining parameter at their standard value.

The study manifested table 4 following facts.

1. $T^{*}$ is no sensitive to the change in the parameter $a, b, \alpha, \beta$ but it is also obtained that it is moderately sensitive to the vary in the parameter $\delta$.

2. The study of observation that optimal order quantity $O Q^{*}$ is highly sensitive to the change in demand parameter $a$ whereas moderately sensitive of $O Q^{*}$ is observed to the $b, \beta$ while it is slightly sensitive to change in backlogging parameter $\delta$ and no sensitive to the change in the parameter $\alpha$.

3. Optimal average profit $T P F^{*}$ is highly sensitive due to the change in the value of its parameters $a, b$ and it is slightly sensitive to the change in $\beta$ and the backlogging parameter $\delta$ and there is moderately sensitive to changes in $\alpha$.

\section{Conclusions}

This paper presents the two-warehouse deteriorating inventory system in which it is assumed that demand rate is stock dependent. At first demand are satisfied from an RW to reduce the loss due to higher rental of RW, but RW offers a better preserving facility that result a low deteriorating rate in comparison with $\mathrm{OW}$. Total optimal profit, the optimal cycle time and optimal order quantity per cycle have been calculated for developed model. The effects of different parameters on the total optimal profit, the optimal cycle time and optimal order quantity per cycle has been observed by sensitivity analysis. Hence the developed model is applicable for a stowing business in order to take economic decision which contributes to enhance the revenue of a company. Besides considering demand as a stock dependent we can take demand as price decreasing and stochastic demand too that will remain future scope of this work.

\section{References}

[1] Skouri K, Konstantaras I, Papachristors S and Ganas I 2009 Inventory models with ramp type demand rate, partial backlogging and Weibull distribution rate. Euro. J. Oper. Res. 192: 79-92

[2] Wee H M, Yu J C P and Law S T 2005 Two-warehouses with inventory models for partial backlogging and Weibull distribution deteriorating items under inflation. J. Chinese Inst. Ind. Eng. 22: 451-462

[3] Yang H L 2006 Two-warehouse partial backlogging inventory model for deteriorating items under inflation. Int. J. Prod. Econ. 103: 362-370

[4] Lo S T, Wee H M and Huang W C 2007 An integrated production-inventory model with imperfect production processes and Weibull distribution deterioration under inflation. Int. J. Prod. Econ. 106: 248-260

[5] Skouri K and Konstantaras I 2009 Order level inventory models for deteriorating seasonable/fashionable products with time dependent demand and shortage. Math. Problem Eng. 2009: 1-24

[6] Yang H L 2012 Two-warehouse partial backlogging inventory models with three-parameter Weibull distribution deterioration under inflation. Int. J. Product. Econ. 138: 107-116

[7] Chakrabarty T, Giri B C and Chaudhuri K S 1998 An EQO model for items with Weibull distribution deterioration, shortages and trend demand: An extension of Philip's model. Comput. Oper. Res. 25: 649-657

[8] Dave U and Patel L K 2006 Policy inventory model for deteriorating items with time proportional demand. J. Oper. Res. Soc. 32: 137-142

[9] Ghare P M and Shrader G F 1963 A model for exponentially decaying inventory. J. Ind. Eng.14: 238-243

[10] Giri B C, Jalan A K and Chaudhuri K S 2003 Economics order quantity model with Weibull deterioration distribution, shortages and ramp-type demand. Int. J. Syst. Sci. 34: 237-243

[11] Hariga M A 1996 Optimal EOQ models for deteriorating items with time-varying demand. J. Oper. Res. Soc. 47: $1228-1246$ 
[12] Misra R B 1975 Optimal production lot-size model for a system with deterioration inventory. Int. J. Prod. Res. 13: 495-505

[13] Philip G C 1974 A generalized EOQ model for items with Weibull distribution deterioration. AIIE Trans. 6: 159-162

[14] Teng J T Chern, M S Yang H L and Wang Y J 1999 Deterministic lot-size inventory model with shortage and deterioration for fluctuation demand. Oper. Res. Lett. 24: $65-72$

[15] Covert R P and Philip G C 1973 An EOQ model for items with Weibull distribution deterioration. AIIE Trans. 5: 323-326
[16] Goyal S K and Giri B C 2001 Recent trends in modeling of deteriorating inventory. Eur. J. Oper. Res. 134: 1-6

[17] Jaggi C K and Tiwari S 2014 Two-warehouse inventory model for non-instantaneous deteriorating items with price dependent demand and time-varying holding cost. Math. Model. Appl. 225-238

[18] Daultani Y, Kumar S, Vaidya O S and Tiwari M K 2015 A supply chain network equilibrium model for operational and opportunism risk mitigation. Int. J. Prod. Res. 53: 5685-5715 